\title{
Experiencing Structure in Penderecki's Threnody: Analysis, Ear-Training, and Musical Understanding
}

MARIUSZ KOZAK

\begin{abstract}
Elliott Carter once extolled the visceral, primitive effect of Penderecki's Threnody on untrained listeners. In this article, I examine how a formalized analytical approach to the central section of the piece contributes positively to a phenomenological experience of the whole piece. Part 1 presents an ear-training progression aimed at bringing to attention some important structural relationships between pitched elements of the passage, including pitch-space transformations that act on chordaldensity compressions. Part 2 initially questions the relevance of transformational analysisconstrued as an enactment of a particular kind of understanding-to the experience of Threnody, ultimately favoring a transformational hearing of the work. The conclusion points out how a rationalized ear-training allows a listener to chart an auditory course through the passage and how the resulting experience can illuminate a new way of conceptualizing Penderecki's intricate sonic materials.
\end{abstract}

Keywords: Penderecki, Threnody, transformations, ear-training.

W riting some three years after the premiere of Penderecki's Threnody: To the Victims of Hiroshima (1960)-originally titled 8'37"-Elliott Carter praised the piece's powerfully poignant effect on listeners. ${ }^{1}$ What he noted in particular was its "anti-artistic" expression, whereby the very severe, harsh sonic effects that the composer created receive justification from the experiential goals of the work as a whole. For Carter, the raw, fundamental, even "primitive" sounds that Penderecki elicits from the orchestra point to the physicality of sound production, ${ }^{2}$ to the acting body that is somehow present both in and behind the music. ${ }^{3}$ As Carter saw it, this "can have a wide appeal on a simple sensuous level and often attracts those not trained to

The author wishes to express his deepest gratitude to Steven Rings, Richard Hermann, Julian Hook, and Joseph Dubiel, as well as the anonymous reviewers and the editorial staff of Music Theory Spectrum, for their insightful comments and invaluable suggestions on earlier drafts of this article.

I Carter (1963). Penderecki was advised to change the piece's title in advance of submitting it to a UNESCO competition in France (Thomas 2005, 165).

2 It is unclear whether the word "primitive" is meant to describe Carter's impression of individual sounds, or of their organization (Carter 1963, 202). In both cases, one should take issue with his characterization. With regard to form, Penderecki's use of a canon, as well as the long-range design shown by both Mirka (2000) and myself below, points to a very sophisticated background of specialized musical knowledge. Meanwhile, branding these sounds as "primitive" belies the highly constructed sociocultural context of string instrument production, of performance, of the relationships between the musicians, between them and the conductor, and so forth. Many thanks to Richard Hermann for pointing this out.

3 The relationship between our perception of musical sounds and our awareness of the human bodies that produce them has been explored with considerable interest in the recent years. Of the plethora of studies that have appeared in the last decade, some more exemplary ones include Cox expect and grasp the higher types of order found in older music."

Indeed, even now, the work can lure listeners into its thick web of historical and cultural associations, in which the horrific sounds provide and sustain a breathtaking background for an excruciatingly emotional release. Of course, thanks to the sobering distance of time, the work also affords a more restrained, cool-headed response. For example, Richard Taruskin writes that, for him, the famous "screams"represented by the piece's opening clusters - can only be identified as screams because they have been marked as such by critics and by listeners since the work's premiere. Meanwhile, after the opening "there is nothing in the piece of a comparably pictorial or suggestive character." ${ }^{5}$ Considering these options, if he were submitting his concert report today, Carter might have drawn on the vast literature emerging from the field of embodied and enacted cognition to delve deeper into the work's "appeal on a ... sensuous level" and its nonlinear, multifarious relationship to listeners' abilities to "grasp the higher types of order." ${ }^{6}$ This juxtaposition of bodily sensations induced by the music with a seemingly rational, analysis-prone ordering of events made possible only with training is particularly telling. It leads us to invoke the idea of embodied experience in order to consider one way in which analysis and

(2011), Godøy (2010), and Clarke (2005). For a critical assessment of some of the claims made therein, see Kozak (2015).

4 Carter points to Stravinsky's Rite of Spring as a precursor to this kind of aesthetic $(1963,202)$.

5 Taruskin $(2005,220)$.

6 Among the plethora of sources on embodiment and enaction, we can point to Varela et al. (1991) as the seminal work that attempted to dissolve the mind/body split in the cognitive sciences. For more recent practical and theoretical developments, see Stewart et al. (2010). 
sensation can productively interact with one another: contra Carter, listening to Threnody is not necessarily a case of "either/or."

Without reflecting on the implications of such a statement, perhaps many readers find themselves asking what kinds of listening attitudes a particular piece of music invites, elicits, or engenders. Indeed, as one of the first steps toward understanding a musical work, this kind of assessment seems well worth it because it positions the listener relative to the piece in a way that can then serve as a starting point for further analysis. Some pieces thus seem to work best with we might call an "intellectual" approach, or what Theodor Adorno refers to as "structural listening." "Further elaborating this notion, he writes of letting a composition "unfold itself in its own terms," so that it may "assert itself" and allow one "to enter into its structure analytically," all of which resonates with the above notions of invitation and elicitation that musicians may ascribe to pieces of music. ${ }^{8}$ With such a strategy, we might look for ways in which the musical surface opens up to reveal an underlying logic, something that we can "grasp" (in Carter's sense above) as a rational progression of sounding events. Meanwhile, other works appear to be better experienced emotionally, viscerally_-with our bodies, rather than with our brains. $^{9}$

Of the two attitudes, Threnody seems to encourage the listener to become emotionally and somatically absorbed in its sounds-it seems to facilitate an engagement with the music's phenomenal experience. At least in Carter's view, this is the default, unmediated reception that does not require an intellectual engagement with the piece. Without doubt, there are plenty of musical elements on display here that typecast the work as resistant to rationalization: thick microtonal textures, lack of articulated and easily identified events, and a continuously unfolding form that, on its surface, precludes traditional notions of design in favor of an unencumbered process. Yet, none of this necessarily disqualifies a structuralist hearing, one based on the development of theoretical and perceptual models

7 Adorno (2002). For an exposition and critique of structural listening, see Subotnik (1995). For responses to Subotnik's deconstructive reading of Adorno, see essays in Dell'Antonio (2004).

8 Adorno $(2002,166)$.

9 Of course, the dichotomy between the brain and the body is a coarse one, since the former is very much a part of the latter, and I am using it here as a heuristic. Thus, in positing these two attitudes I am not claiming that there is a categorical distinction between them, or that one necessarily precludes the other. Indeed, recent embodied extensions to cognitive science (see n. 7 above) provide evidence supporting the view that rational thought is in no way divorced from our bodily states, and that our actions in response to the world's solicitations are as much a part of our cognition as abstract reasoning. Rather, what I am suggesting is that as a way "into" a piece of music it is possible that some works promote a deliberate suppression of explicit bodily exertions in favor of a more detached, even atemporal, study of its structural components. One of the many ways in which composers can achieve this is by eschewing regular pulses, thereby attenuating the listeners' abilities to spontaneously entrain to and move in synchrony with the music (see London 2012). and which allows a listener to approach the piece with an ear for such concepts as structure, logic, and coherence. Quite the contrary; an analytical appraisal of Threnody can enhance, rather than impede, one's embodied, sensual experience.

One theoretical model for analyzing Penderecki's sonic palette can be found in Danuta Mirka's monograph, The Sonoristic Structuralism of Krzysztof Penderecki. ${ }^{10}$ There, she proposes a method based on ideas adapted from Saussurian structuralism, in which her so-called contrary and contradictory elements are juxtaposed in a compositional system whose "axiom is not a concept of a single sound event, but of sound matter taken in its totality-en masse, so to say."11 Contrary elements are those that, mathematically, "can be modeled as a relation between a given set and its complement," while contradictory ones are modeled by "a relation of two sets, each of them belonging to the complement of the other." ${ }^{12}$ Less formally, contradiction describes an opposition between discrete states (e.g., mobility vs. immobility), while contrariety introduces the possibility of a third term in the opposition (e.g., loud vs. soft dynamics, where the possibility of a "middle" dynamic range also exists). In all cases, Mirka illustrates how the relations between various sonic parameters are modeled by fuzzy sets with obscured boundaries between limit conditions. Sets, that is, in which "the transition between membership and non-membership is gradual rather than abrupt" (containing what is colloquially referred to as "borderline cases"), such that membership is assessed in terms of continuous values between 0 and 1 , rather than in binary terms familiar from classical set theory. ${ }^{13}$

Mirka's goal is to uncover formalizable relationships in a sound world that, according to her, had previously been derided as lacking rational order or logical unfolding. Her most important finding is that there are, indeed, long-range ordering principles that determine how Penderecki treats the kinds of raw and "primitive" sounds that so struck Carter, but that do not operate along the traditional formal paths of linear development. Moreover, she demonstrates how elements other than pitches and harmonies-namely texture, density, articulation, loudness, and timbre-participate in creating structure and cohesion not just in Threnody, but also in the composer's other works collectively referred to as "sonoristic."

Io Mirka (1997).

II Mirka (2000).

I2 Ibid.

I3 Dubois and Prade (1980). For an accessible tutorial on fuzzy sets and their musical application to contour theory, see Quinn (1997).

I4 These include such works as Dimensions of Time and Silence (1960; rev. 1961), Polymorhia (1961), Fluorescences (1961-2), and Anaklasis (1959$60)$. As Thomas $(2005,166)$ points out, with the exception of Threnody (and even then only after a change), all bear scientific-sounding titles, suggesting an experimental approach to sound as a matter of objective investigation, the goal of which was ostensibly to discover its various properties. For more on sonorism, see Mirka (1997, 8); also see a special Englishlanguage issue of the Polish musicological journal Muzyka devoted to the 
Despite her comprehensive approach, mm. 26-48 of Threnody are conspicuously absent from Mirka's large output of analyses, ${ }^{15}$ and it is for this section that I have developed a series of ear-training exercises that involve contextual transformations. In this passage, Penderecki seems to have abandoned the sound-mass procedures found elsewhere in the piece, which perhaps helps explain why it is not treated in Mirka's account. The passage stands out as a relatively independent unit: it appears in the middle part of the large A ( $\mathrm{mm} .1-25) \mathrm{B}(\mathrm{mm}$. 26-61) A' (mm. 62-end) framework on which Threnody is based. Measures 26-48 are audibly distinct from the outer parts, which are less pointillistic and more uniform in terms of sonic processes. In addition, the passage also follows the longest pause in the piece thus far (an interruption of some five seconds duration). The formal technique used here by Penderecki, as pointed out by some scholars, is a canon, ${ }^{16}$ but this design is thoroughly obscured by the timbral and temporal characteristics of each "voice." As a result, it is difficult to hear each subsequent entry as a reinstatement of the $d u x(\mathrm{~mm} .26-37)$. To clarify the auditory space and to bring this structure into focus, as well as to construct a model for a potential hearing of this portion of the work, the forgoing commentary will draw the reader's attention to some of the sonic elements that share common characteristics and propose possible transformations that relate them. Although it is likely that such an analysis might unearth the generative algorithm that Penderecki used in designing this excerpt, the concern here is not in "de-composition" as such. ${ }^{17}$ Instead, drawing on Lewin's 1993 essay on Stockhausen's Klavierstück III, the goal is to present a listening aid which contributes to listeners' active engagement with the piece. ${ }^{18}$

The second section of this article addresses a broader critique of applying "transformational ear-training" to this particular piece. It considers the conceptual and experiential underpinnings of the analysis, including the value of the analytical technique presented

historical genesis and development of the term as a theoretical concept and an analytical tool (Granat 2008).

I5 Here and elsewhere, I use the term "measure" to refer to segments demarcated by vertical dashes in the score. This terminology is used for analytical convenience only and in no way suggests a metric design. For more on the temporal elements in Penderecki's notation, see Mirka (1997, Chapter 13).

I6 Gruhn (1971); Mirka (1997); Taruskin (2005, 219-20).

I7 This is to say that I do not intend to "crack the code" of Threnody in a manner comparable to Lev Koblyakov's (1977) analysis of Boulez's Le Marteau sans maitre, for example. Indeed, there is an important difference between structure as something that can have significant implications for one's auditory experience of a piece of music and as generative algorithms that constitute the pre-compositional process. With this in mind, we can think of the canon itself as a technique used to saturate the texture with enough voices to create an auditory "mass." Meanwhile, the kind of structure posited here need not have had tactical significance for the composer but will, nonetheless, affect the listener's experience. Of course, it is possible that one could learn to hear the canon, but I will not pursue this option herein.

I8 I also acknowledge that there are a number of other ways to listen to these measures, some of which I will point out in the course of the analysis. in the first section, for listening to Threnody. Furthermore, whereas Part I is rather narrowly circumscribed within the norms of transformational analysis-focusing on relationships established by various complexes of pitched musical elements-Part II opens up to a potentially damaging challenge to this method. It is here, in fact, that I develop a critical dialogue between the aims of the ear-training model and the role of "non-structural" events in the construction of listeners' experiences of this piece. The goal of this seemingly Janus-faced approach is to channel this critique into creating a meaningful encounter with the Threnody - one of many possible encounters - that subsumes some of the less formalist epistemological foundations of transformational technology (the "transformational attitude") within a broader field of contemporary listening strategies. ${ }^{19}$

Let us first note that the passage under discussion, in which the whole ensemble is split into two Orchestras (I and II), displays a wide gamut of varying articulations. ${ }^{20} \mathrm{We}$ can arrange these articulations according to their most general sonic characteristics: $\operatorname{arco}(\mathrm{A})$ and percussive $(\mathrm{P})$. Designation $\mathrm{A}$ applies to all the types of articulation in which any part of the bow (i.e., hair and stick) is used to produce sustained tones of determined duration. In contrast, elements $\mathrm{P}$ are characterized by an indeterminate duration. Example 1 represents this division; Example 2 shows a reduction of the first four measures of the fragment, with annotations illustrating the categorization of elements into $\mathrm{A}$ and $\mathrm{P}$ (the former are further subdivided into $A n$ and Ad as explained below).

Example 3 reproduces the temporal arrangement of A and $\mathrm{P}$ elements in Orchestra I from m. 26 to m. 48. Measure 37 is excluded because, in it, the previous sonority is sustained but without a change in articulation. In m. 38, Orchestra II repeats Orchestra I's material in a "visual" inversion of sorts around the Viola 2/Viola 3 axis. ${ }^{21} \mathrm{I}$ have separated the example at $\mathrm{m} .38$ to illustrate that this and the following measures in

I9 The phrase "transformational attitude," which emphasizes process over state, first appears in Lewin (1987, 159). Klumpenhouwer (2006) states that the attitude in general is essential to Lewin's project, which crucially rests on its "anti-Cartesianism" even while its use of mathematics to solve music-theoretical problems betrays a debt to Descartes. However, Hook (2007) argues instead that the notion of an attitude forms a surplus in transformational technology beyond mathematical formalism that can be simply referred to as "function" and has, therefore, been overemphasized in its consequences for the analytical process. Perhaps a better word here is simply "transformational hearing." Whereas "attitude" suggests a general, nontemporal comportment or intentionality (Rings 2011b), this change in nomenclature points to the way in which listeners organize their experience in time.

20 Although clusters play a role here to a certain extent (for instance in $\mathrm{mm}$. 35-37), I will set aside this particular sonoristic technique for the time being.

2I It is not a strict inversion in the sense of canonical transformations, as will be seen shortly. The reader will also note that $\mathrm{mm}$. 43-49 in Orchestra I are a retrograde "visual" inversion of $\mathrm{mm}$. 35-42. 


\begin{tabular}{|l|l|}
\hline Arco (A) & Percussive (P) \\
\hline arco & pizzicato (pizz.) \\
\hline sul ponticello (s. p.) & tapping the body of the instrument (f) \\
\hline harmonics & legno battuto (l. batt.) \\
\hline tremolo & \\
\hline con sordino (c. s.) & \\
\hline col legno (c. 1.) & \\
\hline
\end{tabular}

EXAMPle I. Division of sound events into arco $(A)$ and percussive $(P)$. Abbreviations and symbols in parentheses indicate how these events are represented in the score.

Orchestra I (labeled Sec1, for "section 1") constitute an accompaniment/countersubject to Orchestra II and is therefore a separate section from mm. 26-37 (labeled Sec2). The "repose" in mm. 35-37 further supports this segmentation, which results from a change in articulation and texture from earlier material consisting of instruments playing in two groups, with uniform articulation in each group, and together sustaining two microtonal clusters. The resulting effect is in contrast to previous and following measures, where each instrument is treated soloistically with its own articulations. The rates of change in both articulations and registers slow down sharply here, perceptually demarcating this moment as a separate event.

There is a noticeable increase in $\mathrm{P}$ elements from Sec1 to Sec2. In Sec1, the cardinality of $\mathrm{P}(\# \mathrm{P})=12$ and the cardinality of $A(\# A)=35$, resulting in the ratio $A: P$ of 2.92. In Sec2, $\# \mathrm{P}=22$ and $\# \mathrm{~A}=30$, resulting in the ratio $\mathrm{A}: \mathrm{P}$ of 1.41. One way to conceptualize this is in the relationship of Orchestra I to Orchestra II in Sec2. Since Orchestra II repeats material from Sec1, where the predominant articulations were arco, the increase in P in Orchestra I allows A elements in Orchestra II to clearly stand out in the sonic texture. In other words, elements $\mathrm{A}$ and $\mathrm{P}$ have such distinct acoustical properties that it is easy to discern between them in listening.

Within Penderecki's extended timbral palette, each element in group A can be further subdivided into two categories: (1) sustaining a discrete pitch (labeled Ad), or (2) sustaining a nondiscrete pitch (e.g., playing between bridge and tailpiece, behind the bridge, or on the bridge itself at a right angle at its right side; labeled An). Example 4 reexamines Sec1 and Sec2 according to this distinction. Notice that Sec1 includes a fragment of a continuous, uninterrupted succession of Ad elements. In contrast, Sec2 contains primarily An elements. This suggests that Sec1 of Orchestra I can be perceived by focusing on discrete pitches, the collections they form, and the transformations between these collections. It further indicates that the section played by Orchestra II in mm. 38-47 (let us call it Sec1') can also be perceived in this manner, because Ad elements are fundamental to modes of hearing taught by Western conservatory ear-training programs and are, in general, acoustically distinct from An elements. Based on these hypotheses, let us examine pitch progressions in Sec1 and Sec1', first as modeled abstractly in pitch-class space and later as realized by Penderecki in pitch space.
Example 5 shows the important vertical sonorities of Sec1 in Orchestra I, mm. 26-35, most of which consist of three voices forming members of set-class 3-1[012] and which are identified with italicized upper-case letters above and to the left of each system. ${ }^{22}$ Letters below systems indicate pitch classes. The arrangement of set-classes 3-1[012] is more or less consistent from beginning to end, with a couple of exceptions. First, the very opening sonority (B, $\mathrm{C} \sharp, \mathrm{D}$, labeled $A$ in the example) forms a member of set-class 3-2[013] instead. The missing pitch class, $\mathrm{C}$, does indeed sound in close temporal proximity (pizzicato in Viola 1 on the second quarter note in m. 26); however, to remain consistent with our focus on $\mathrm{Ad}$ elements, I have excluded it from the model. The second exception occurs at the very end of the passage, mm. 33-35. Here, the sounding pitch classes are $\mathrm{D}$ and $\mathrm{C} \sharp$ (see $H$ in the example), which are common to sonority $A$ in the beginning. We could, therefore, construe of sonority $A$ as made up of two different sonorities: a $\{C \sharp D\}$ dyad, and a $\{B\}$ monad. Such an arrangement of elements would allow us to consider sonority $H$ as a closure of the progression set in motion by sonority $A$.

An unusual moment occurs in mm. 31-32 (sonority $F$ ), where, instead of three, five pitch classes are sounding simultaneously. Together, they form set-class 5-1[01234], which, like set-class $3-1[012]$, is characterized by interval-class 1 . However, rather than thinking of this sonority as a five-note simultaneity, which is suggested by the registral proximity of all pitches, we can subdivide it into two sonorities based on articulations and durations. Thus, $\{F F \sharp G\}$ could constitute one sonority, $F b$, because all three pitches are of the same duration (half-note plus a sixteenth) and are articulated sul ponticello. In contrast, $A$ and $A b$ are articulated con sordino and arco, respectively, and both last a quarter plus a dotted-eighth. We can, therefore, consider this moment in two ways: (1) it comprises two three-note sonorities of set-class 3-1[012], in which $\mathrm{G}$ acts as a common pitch connecting them (in this case, our established model of three-note successions remains undisturbed); (2) A and Ab form a two-note sonority of set-class $2-1$ [01], which is closely related to sonority $A$ (minus the $\mathrm{B}$ ) and sonority $H$. In this case, our model is disturbed, but we

22 Although the score does specify quarter-tones elsewhere in the piece, in this section only the twelve chromatic pitches are used. 


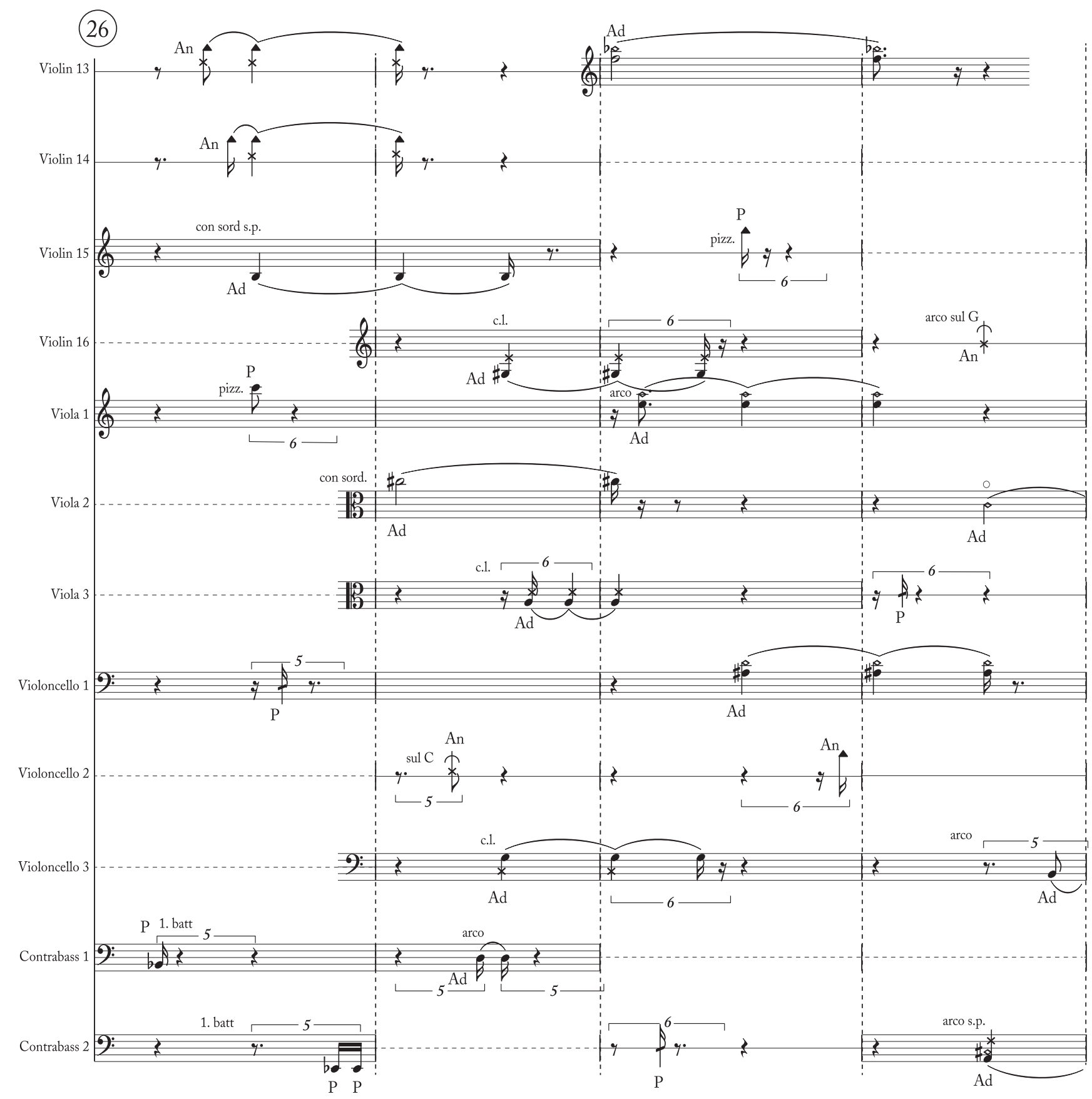

EXAMPle 2. An annotated score of mm. 26-29, showing elements arco pitched (Ad), arco non-pitched (An), and percussive (P)

have further support of the reading proposed in the paragraph above. However, regardless of which reading we do decide upon, what remains is that sonority $F$ continues the ic1 relationship between pitch classes that has been established from the beginning. I opt for the first interpretation below because of its analytical elegance, but the second alternative could prove viable as well if one were to pursue it further.

Example 6(a) represents Sec1 in pitch-class space as an abstract network. The nodes contain sonorities labeled with letters corresponding to the previous example, and the arrows represent transformations, which, in this case, are canonical transpositions. Although initially there may be nothing remarkable about this network, one important implication for my ear-training model is immediately made evident. Instead of latching on to seemingly random pitch simultaneities, the listener can now learn to hear the progression using nothing more than ordinary, run-of-the-mill transpositions. In fact, Example 7 shows a realization of this network that can be 
$\mathrm{A}=\operatorname{arco}$

$\mathrm{P}=$ percussive

$\%=$ no change

Sec1:

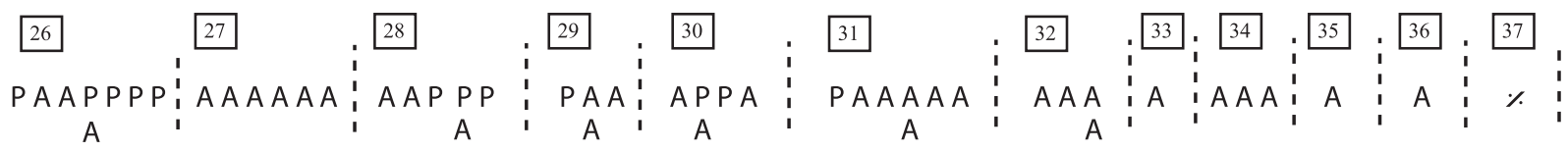
$\# \mathrm{~A}=35 \quad \mathrm{~A}: \mathrm{P}=2.92$ $\# \mathrm{P}=12$

$\operatorname{Sec} 2$ :

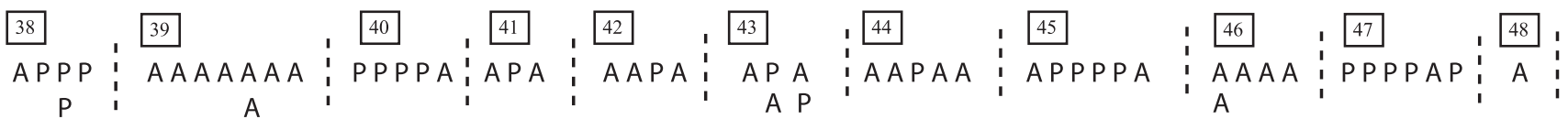

$$
\# \mathrm{~A}=31 \quad \mathrm{~A}: \mathrm{P}=1.41
$$

$\# \mathrm{P}=22$

EXAMPLE 3. Temporal arrangement of elements $A$ and $P$ in Sec1 and Sec2 (Orchestra I only)

Sec1 (Orchestra I):

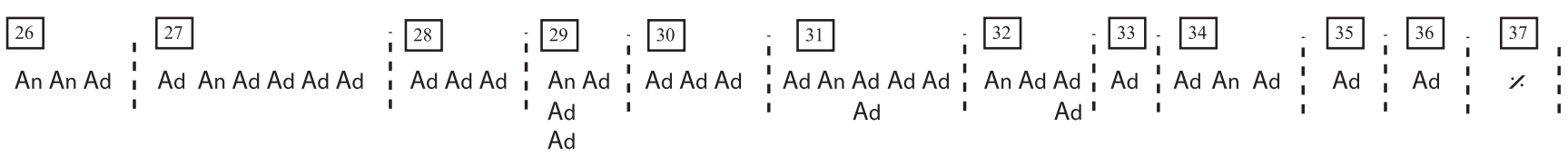

$\# \mathrm{Ad}=28 \quad$ Ad:An $=4.00$

$\#$ An $=7$

Sec2 (Orchestra I):

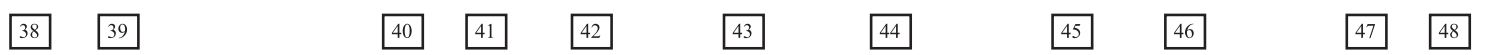

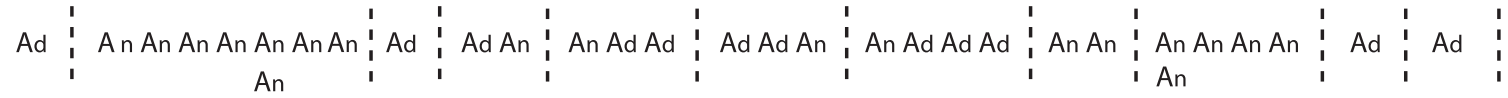

$\# \mathrm{Ad}=12 \quad$ Ad:An $=0.63$

$\#$ An $=19$

EXAmple 4. Temporal arrangement of elements Ad and An in Sec1 and Sec2 (Orchestra I only) 


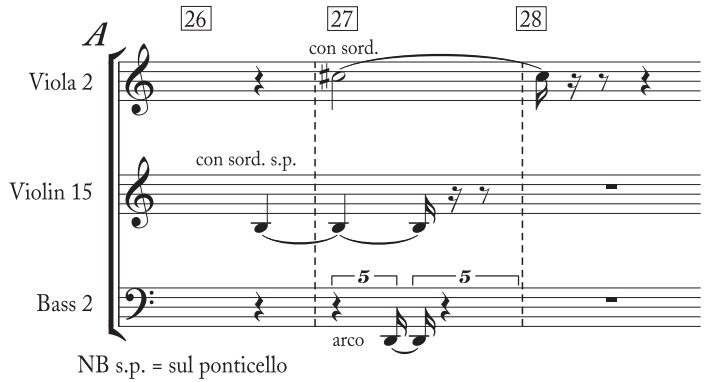

(B) $\mathrm{CH} \mathrm{D}$

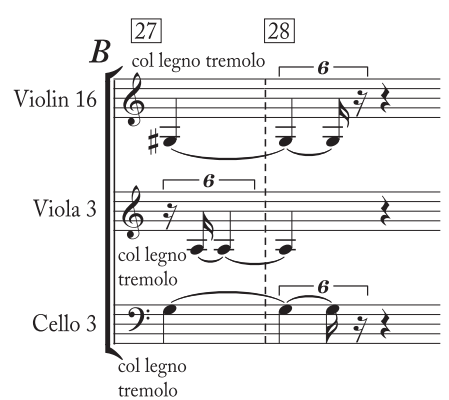

G G\#A

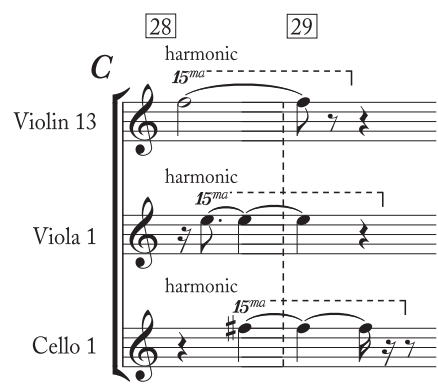

EFF\#
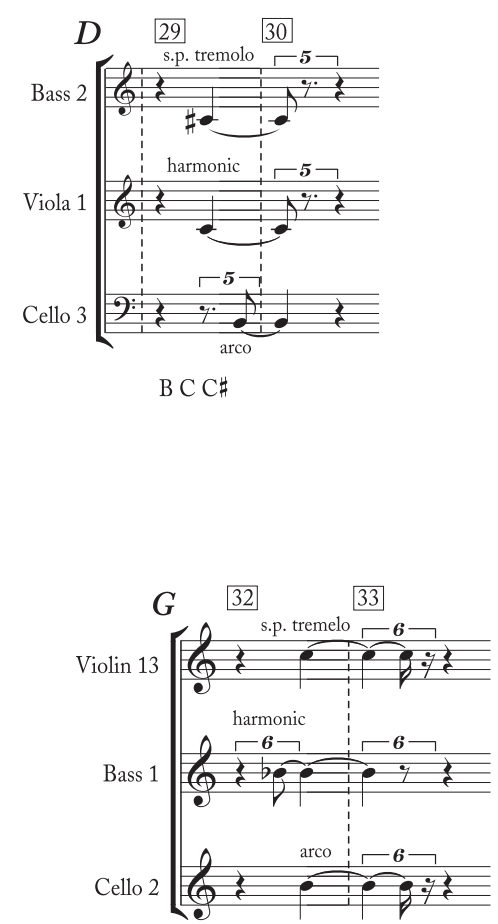

Bb B C

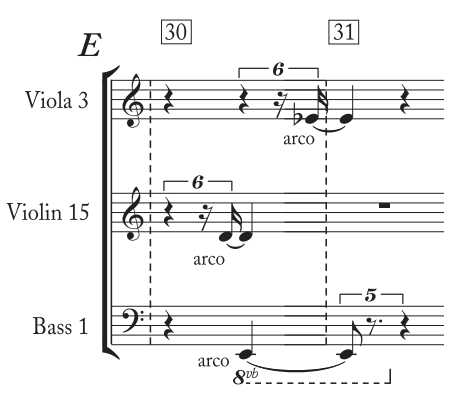

$\mathrm{DEE}$
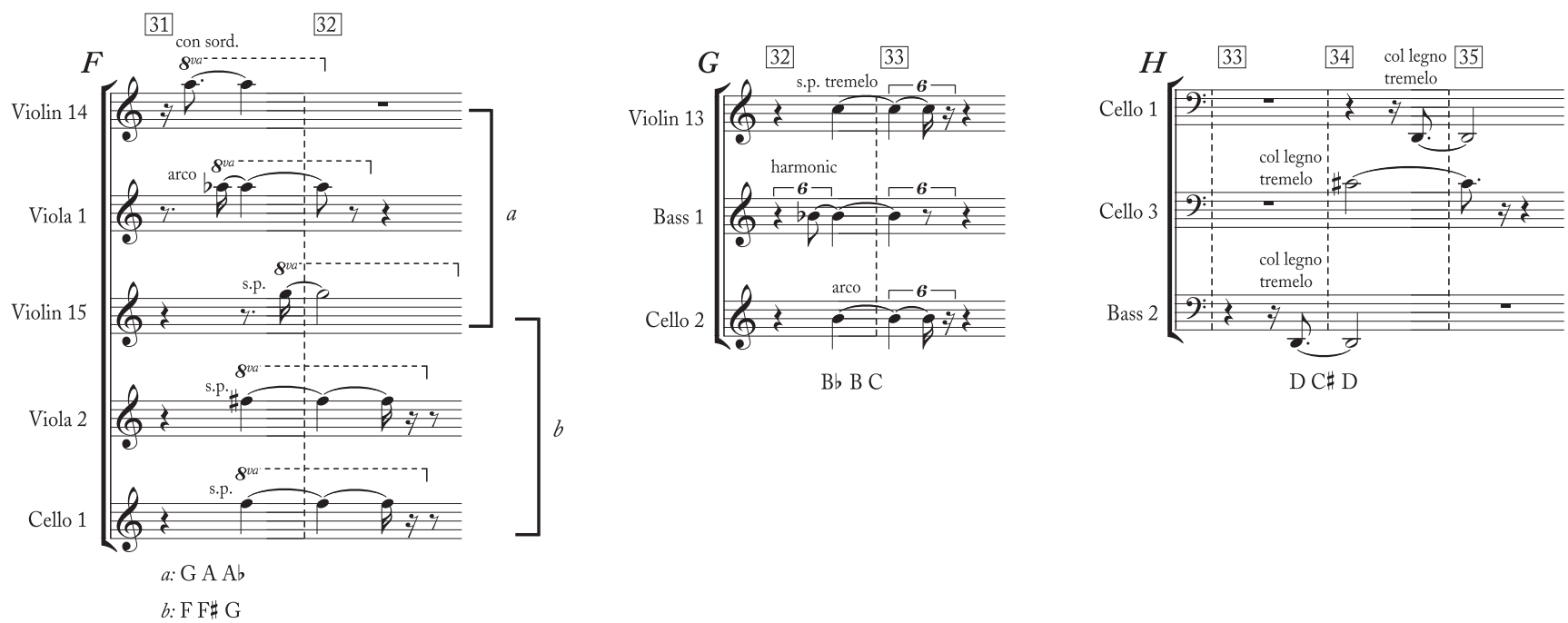

$\mathrm{DC} \# \mathrm{D}$

EXAmple 5. Vertical sonorities in Sec1 (Orchestra I, mm. 26-35; sounding pitches)

played on the piano and can serve as the first stage in developing "an ear" for the passage. ${ }^{23}$ Note that the $\mathrm{B}$ in sonority $A$ is in brackets to intimate a "fuzzy" transposition in which we focus solely on the $\mathrm{C} \sharp-\mathrm{D}$ similarity between $A$ and $H$ while, at the same time, acknowledging its presence in our auditory experience.

23 This is, of course, an explicit nod to Lewin (1993).
Looking once again at Example 6(a), let us consider sonority $E$ as a medial articulation around which the remaining sonorities are arranged. ${ }^{24} \mathrm{An}$ interesting relationship exists between progressions $A \rightarrow E$ and $E \rightarrow H$ : both end with the same transposition, $\mathrm{T}_{3}$, resulting in a return to $\{C \#, D\}$ in

24 This neat arrangement is facilitated by my choice of interpreting sonority $F$ as two three-note simultaneities, as observed above. 
(a)

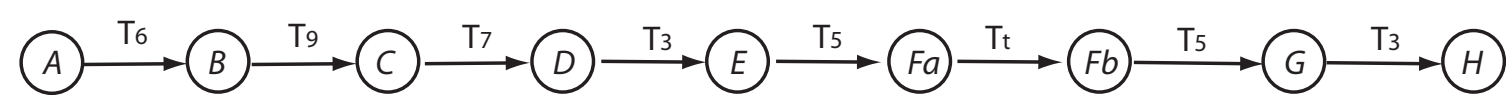

(b)

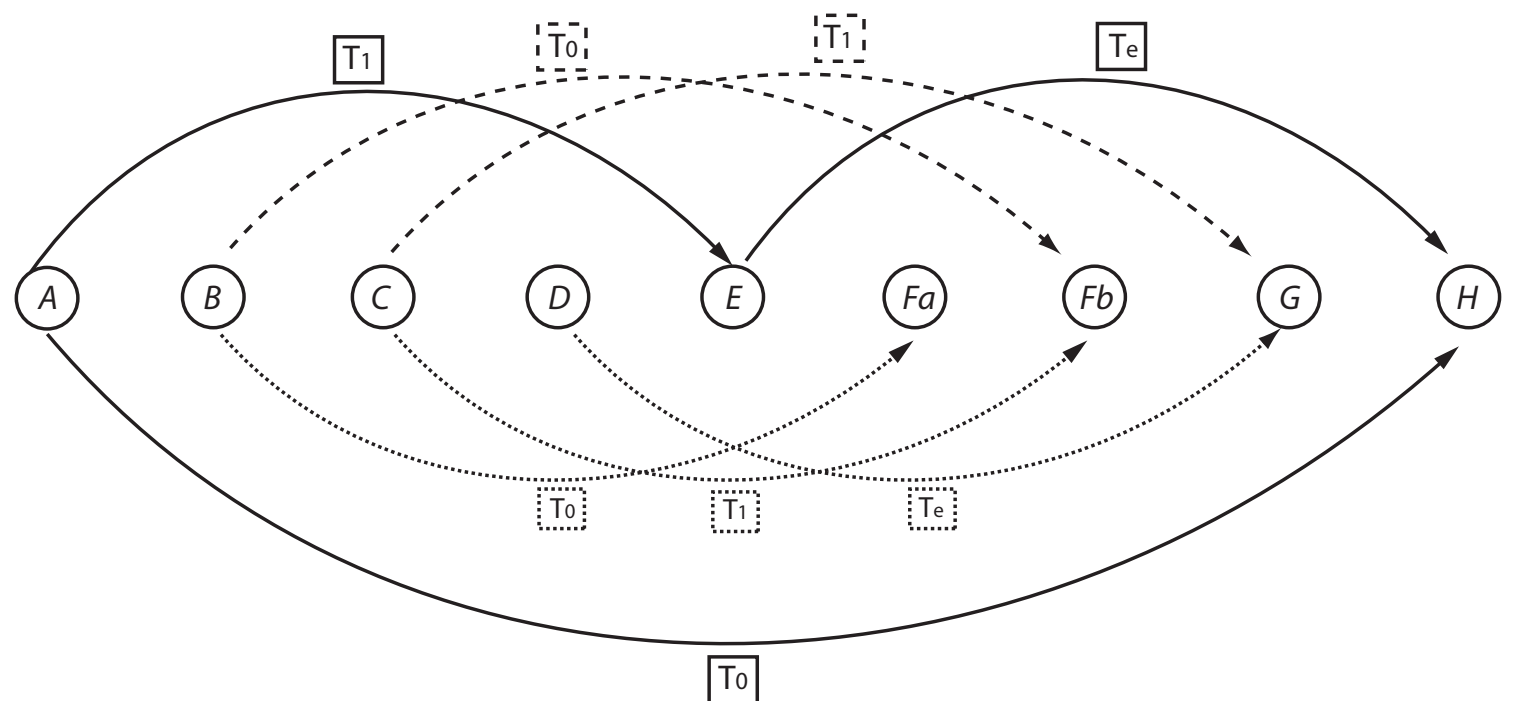

EXAMPle 6. A network of (a) adjacent and (b) non-adjacent transpositions in Sec1 (Orchestra I, mm. 26-35)

sonority $H$ that was initiated by sonority $A .{ }^{25}$ Furthermore, the transposition from $A$ to $E$ is $\mathrm{T}_{1}$, whereas the transposition from $E$ to $H$ is $\mathrm{T}_{11}$, which are inversions of one another. In the model shown in Example 7, one can hear this relationship by simply playing sonorities $A, E$, and $H$ in succession, which makes it possible to internalize the half-step motion between them. Example $6 \mathrm{~b}$ shows a network of similar half-step relationships that arise from our arrangement of sonorities around $E$. Notice, for example, that $G$ is both a $\mathrm{T}_{1}$ transposition of $C$, and a $\mathrm{T}_{11}$ transposition of $D$. Once again, playing the sonorities in Example 7 will help in perceiving the relationships between them. Below we will see how Penderecki realizes these relationships in pitch space.

As stated earlier, Orchestra II repeats in mm. 39-47 the material stated initially by Orchestra I. The reader will recall that the statement of Orchestra II, Sec1', is a "visual inversion

25 As per Lewin's $(1987,3)$ definitions, the operations from $E$ to $H$, and from $G$ to $H$, are actually functions ("onto," but not "1-to-1") because of the different cardinalities of the two sonorities in each pair (numbers 3 and 2 , respectively). However, we can theoretically posit a third pc in sonority $H, \mathrm{D} \sharp$, based on the fact that it appears later in the corresponding sonority $H^{\prime}$ (m. 45), in which case the transpositions shown in the network in Ex. 6(a) materialize. about the viola 2/viola 3 axis" of Sec1. This inversion is not, however, executed in its strict, canonical sense (something that can be seen by comparing Ex. 5 with Ex. 8). Instead-and surprisingly-the pitch content of the passage's sonorities almost exactly matches that of Sec1. Therefore, the abstract network from Examples 6(a) and 6(b) for the most part applies also to Sec1'. There are, however, a few interesting exceptions. First, observe that sonority $A$ is missing pitch-class $\mathrm{B}$ that was present in the corresponding sonority $A$. This not only supports our omission of $\mathrm{B}$ from the above network but also creates a continuation from sonority $H$, which ends Sec1. Second, sonority $D^{\prime}$ has an interesting pitch-class structure compared to its earlier counterpart, $D$, as well as within its own context. Rather than belonging to set-class 3-1[012], its pitch classes make up set-class 3-5[016]. Despite the fact that this set class introduces variation into the established model, the outer interval of a tritone has its own prominent aural properties that can help situate the listener within the context of the passage. Lastly, sonority $H^{\prime}$ is slightly different from sonority $H$ in that the former belongs to set-class 3-1[012] and the latter to setclass 2-1[01], even though they both contain three sounds: the doubled $\mathrm{D}$ in $H$ now becomes $\mathrm{D} \sharp$. While this new sonority conforms to our model, it slightly alters the formal design of 


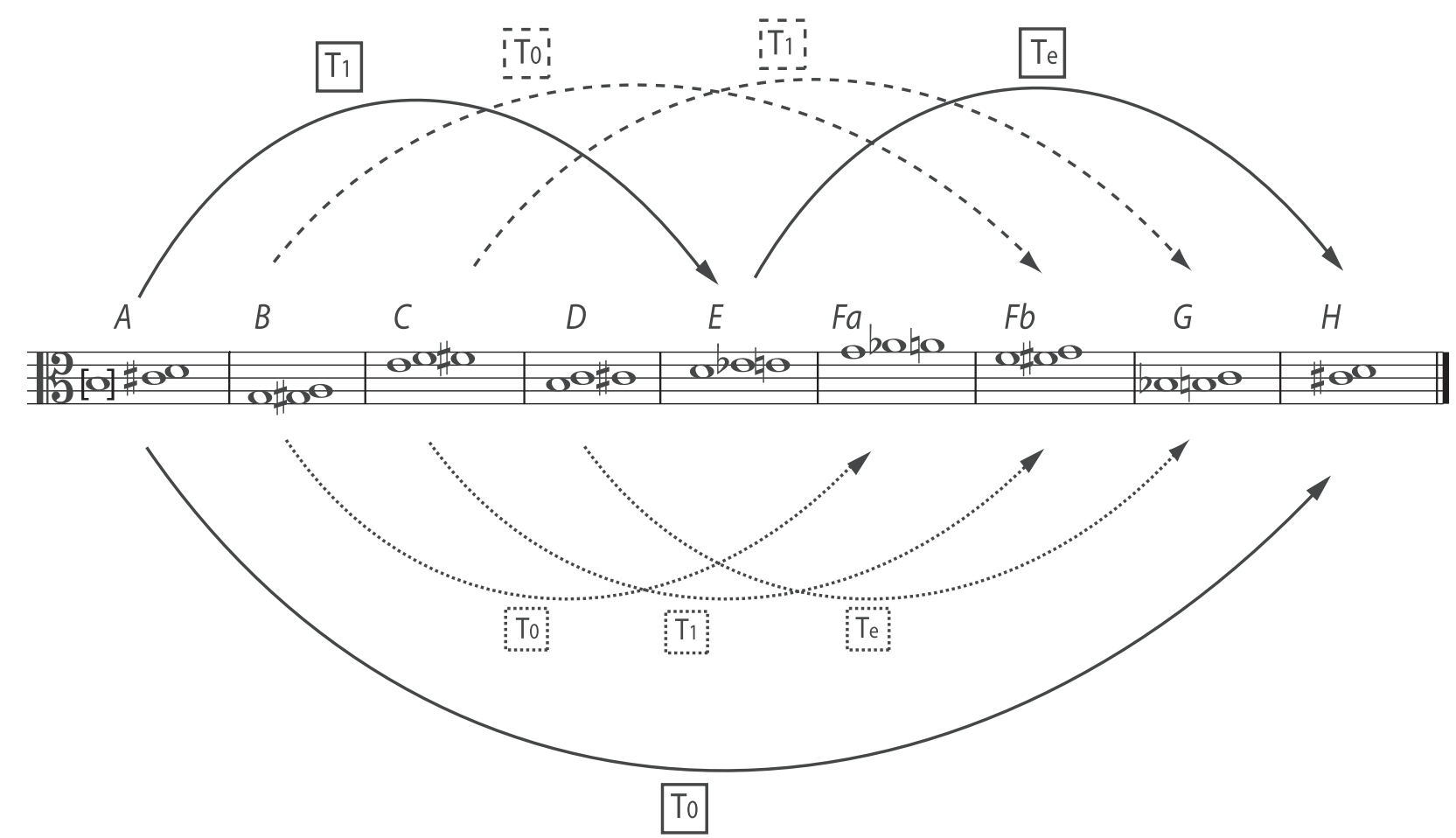

example 7. A piano realization of the pitch transposition network

the canon. Yet, the sonic quality of the sonority is maintained because $\mathrm{D} \sharp$ in violin 17 and $\mathrm{D}$ in viola 4 overlap only slightly, leaving room for the ic1 between $\mathrm{C} \sharp$ and $\mathrm{D}$ to remain the last aurally perceptible sound.

The pitch classes that disturb the neatness of our model offer an opportunity to consider the role that the score's materiality plays in this analysis. Namely, Penderecki's unusual symbols required music publishers to create new templates, which, given the visual complexity of the composition, could very well have resulted in certain notational errors. ${ }^{26}$ In fact, the reader can confirm that each pitch that does not fit my analysis could be "fixed" by a simple addition of symbols that can be easily overlooked in preparing a music manuscript for print: ledger lines, clef changes, or accidentals. This justifies labeling the sonorities in Sec1' as $A^{\prime}-H^{\prime}$, rather than $I-P$, in order to more clearly demonstrate their correspondence with Sec1. Further muddling the matter, there exist at least two original manuscripts of Threnody. Penderecki completed the

26 The genesis of Penderecki's notation is an interesting study in itself. One curious observation (relayed by Erhardt, 1975) is that, at the time of writing sketches for Threondy, the composer lived in a tiny one-bedroom apartment in Warsaw along with his wife (and her grand piano!), motherin-law, five-year-old daughter, and, on top of it all, a dog. It is not surprising that Penderecki was often seen working at a local coffee shop, where tiny tables forced him to frugally employ a notational shorthand. While sketching Threnody, the composer decided that the unusual shapes more effectively represented the essence of his sonic ideas and subsequently abandoned regular notation altogether. first manuscript in two days in the spring of 1960 and submitted it to the Grzegorz Fitelberg Composition Competition (where it received third place). In winter of the same year, he was forced to create a second "original," which he sent to Polskie Wydawnictwo Muzyczne for publication. This second manuscript was created from memory when the composer visited France, because the first score was lost in the mail. Six months later, when the original original was finally recovered, it became clear that customs officials had confiscated it in order to decipher its unusual figures, thinking that they had encountered a secret code. Although a comparison of the two manuscripts by the composer at that time revealed "no significant differences," it is possible that some small changes went unnoticed. ${ }^{27}$ Still, the overall timbral character of the passage from m. 26 onward remains undisturbed even if not every pitch fits the model outlined above.

Until now, I have been discussing simultaneities in their most abstract form as sets of pitch classes. Let us return to Example 5 and examine their realization in pitch space. Penderecki explores the entire pitch range that is made available by the instruments at hand: from the lowest $E_{1}$ in the bass (sonority $E$ ) to "the highest note possible" 28 (one of the elements in An). The resulting sequences of perceptual

27 The above incident is recounted in Erhardt $(1975,29)$. The score used in this analysis was published by Belwin Mills and contains no information about which of the two "original" manuscripts was used as its source; to my knowledge, there exists no critical edition of Threnody.

28 As indicated in the score by the composer. 

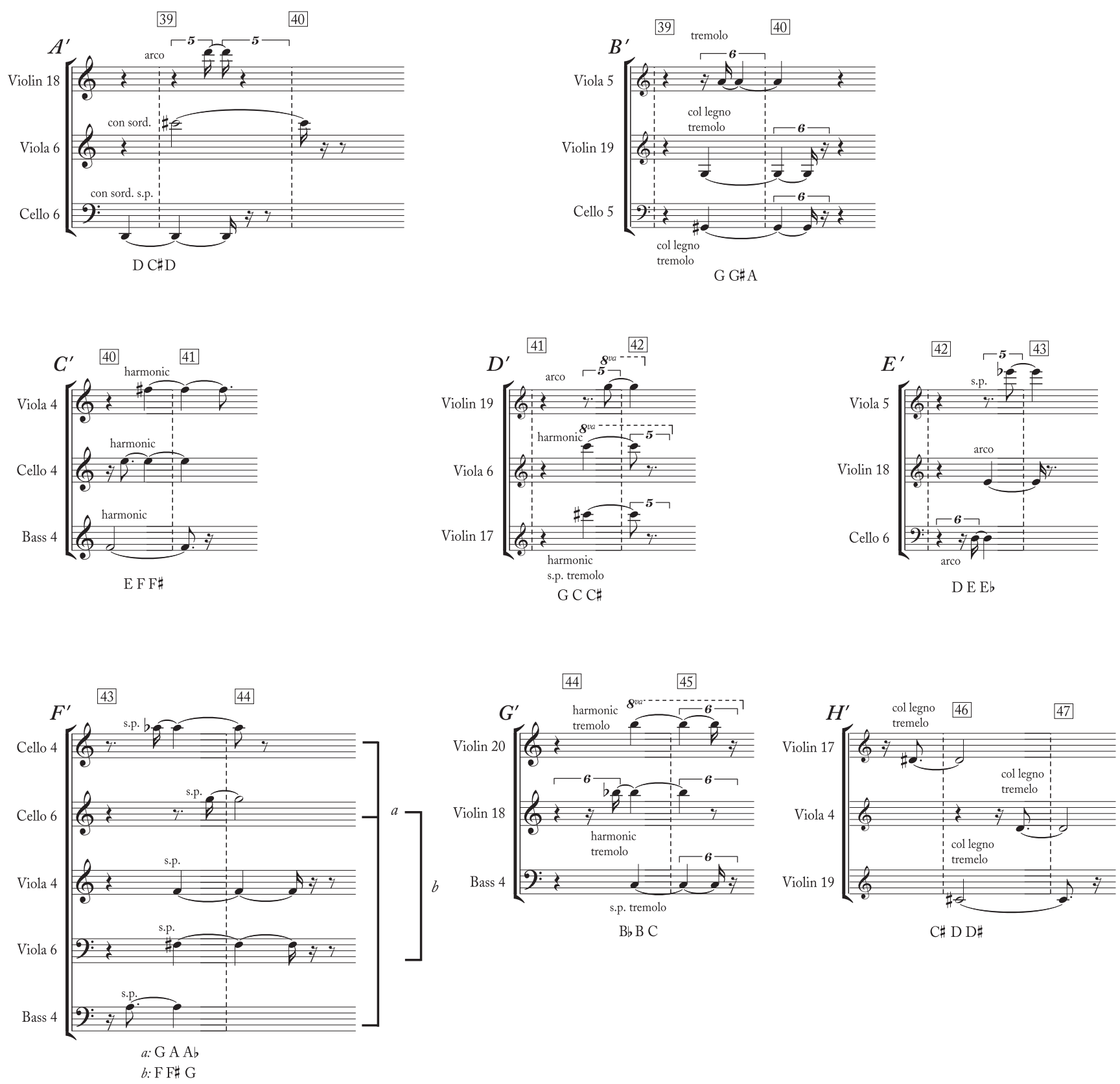

EXAMPLE 8. Vertical sonorities in Sec1' (Orchestra II, mm. 38-47; sounding pitches)

discontinuities do not make for the easiest listening experience, as one's attention has to constantly shift from one register to another. However, since texture is such an important aspect of Threnody, we can attempt to train our ears to anticipate various textural transformations in connection with the pitch-class transpositions discussed earlier. In what follows, I will borrow Wallace Berry's general concept of density compression, which refers to the intervallic content of a sonority. Although Berry quantitatively expresses density compression as "the ratio of the number of sounding components to a given total [pitch] space," I present a slightly different formalism based on occurrences of pitch interval $1 .^{29}$

Sonority $A$ in Example 5 is realized in pitch space spanning an interval of thirty-five semitones from its lowest pitch $\mathrm{D}_{2}$ to its highest $\mathrm{C}_{5}$. The sonority contains no literal pitch interval of one semitone; therefore, we can say that it is maximally diffused (maxdiff). The following sonority $B$ contains two pitch intervals of 1 ; thus, it is minimally diffused (mindiff). In our model, let us position elements maxdiff and mindiff as the

$29 \operatorname{Berry}(1987,209)$. 
most extreme entities on a density compression scale. Let maxdiff represent a pitch-space realization in which there are no pitch intervals of 1 ; consequently, let mindiff be a state in which all adjacent pitches are interval 1 apart. The third element on the density compression scale will be a pitch-space realization in which only two adjacent pitches are one semitone apart, while the other interval is greater than 1 . Let us call it moderately diffused (moddiff) and place it between the two extremities. In Example 5, sonorities $D$ and $E$ represent this level of density compression. Further, let DFUSE constitute a transformation that acts on the space of diffusion (diff) states by increasing $(+)$ or decreasing $(-)$ the number of occurrences of interval $1 .^{30}$ The textural transformation from sonority $A$ to sonority $B$ is thus DFUSE-; its inverse is DFUSE + , seen for example between sonorities $C$ and $D$. If the succession of sonorities results in no change in density compression, then let us call it DFUSE0, the identity element. An example of this occurs between sonorities $B$ and $C$.

The entire textural progression of Sec1 in terms of changes of density compression is represented by the network in Example 9(a). Notice that since we added an intermediary term moddiff, the transformation from $A$ to $B$ has become DFUSE2. We intuit this because a transformation from mindiff to maxdiff involves two steps in our model. At the same time, we must note that the formalism here is rather loose, due to the fact that DFUSE transformations do not form a group: performing DFUSE +1 transformations on a maxdiff collection of pitches will not yield a new member of the diff set. This actually captures my aural intuition because the metaphor of diffusion, when applied to simultaneities in pitch space, seems to work in only one direction. Continual diffusion will not "wrap the pitch space around itself" and result in mindiff, rather, we would need to apply its opposite (DFUSE-1, or DFUSE-2). To put it in musical terms, the way in which we typically construe pitch space is linear, extending indefinitely (although eventually limited by our auditory capabilities) in the direction of increasing frequencies, and bounded by some theoretical 0 at its lowest extreme. While under certain circumstances we can think of octave equivalence as a return to the same "place"-motivating perhaps a metaphor of a spiral-such a notion does not apply in the present case. A collection of simultaneously sounding pitches in which there are no instances of pitch interval 1 will simply remain maxdiff regardless of how many times we apply the transformation DFUSE +1 . No doubt many readers can attest for themselves that, beyond a certain point, it becomes difficult to hear the exact compound interval between two pitches, to say nothing of the number of octaves separating them "in any way more precise than 'a lot."'31

Notably, an aurally salient feature of the passage is illustrated by the density compression network, namely that both

30 For more on musical spaces, see Morris (1995). Hermann (1995) models the "spreading" and "contracting" of pitch space in Luciano Berio's Sequenza IV for solo piano using so-called chordal shapes.

3I Rings (2011b, 54). outlining sonorities, $A$ and $H$, are maxdiff; adjacent pairs $(B$, $C)$ and $(G, F a / b)$ are mindiff, finally, the middle pair $(D, E)$ is moddiff. This is a phenomenon that can establish a distinct transformational pattern for the listener. The resulting intervals 1 are aurally very prominent and can help tremendously in hearing this passage, even when articulations and register change dramatically (as between sonorities $B$ and $C$ ).

A different story occurs in Sec1'. As Example 9(b) shows, the primary mode of pitch space realization is maxdiff, thus creating a kind of "fuzzy" inversion of the previous network. Here, all but three sonorities- $A$ ', $F a^{\prime}$, and $H$-exhibit maximum diffusion, resulting in almost no intervals 1 . Even of the three just listed, only $H^{\prime}$ represents mindiff, whereas the other two are moddiff. Despite a lack of the aurally prominent interval 1 , the textural transformations in this section create an elegant continuity that can establish and confirm listeners' expectations and can thus aid in hearing the passage as a systematic progression of related events. This continuity arises from the fact that almost all textural transpositions are DFUSE0; thus, keeping one attuned to the openness of the space range can become a unifying aspect of this passage. In terms of ear-training, this aspect can be practiced by first playing each section separately, as suggested in Example 10, followed by playing each corresponding pair of sonorities from Sec1 and Sec1' in succession, shown in Example 11. In the first method, which realizes Example 9 in pitch space, listeners can explore different textural transformations separately and can then use the second method to establish expectations for hearing Sec1' in comparison to Sec1. An advantage to playing these excerpts on the piano is that one can realize an important kinesthetic aspect of DFUSE transformations: one's fingers and hands literally spread from lower to higher density sonorities and return together by progressing in reverse. ${ }^{32}$

II

A serious criticism that could indict the entire enterprise presented in the first part of this article concerns what we might broadly describe as the ethics of an ear-training analysis: just because one can suggest a formalized hearing for the passage in question does not necessarily mean one should. ${ }^{33}$ More than mere handwringing, this concern addresses the strain between structure and experience at the forefront of several recent

32 The above analysis examines the density compression network as a formal representation of temporally unfolding processes, where the arrows can be considered as analogous to the listener's perspective (Lewin's "figural" and John Roeder's “event” networks; see Rings 2011b, 140-1). Another way of looking at the DFUSE transformations between sonorities might be as an out-of-time space of all available diff states, akin to spatial networks found in Rings (ibid.). In the interest of space, I will not pursue this possibility here.

33 A similar point of critique is taken up by Quinn (2006) with respect to minimalist music. One difference is that I attempt to use formal analysis to shape experience, while Quinn is interested in altogether changing the very objectives of such analysis. 
(a) Sec1 (Orchestra I, mm. 26-35)

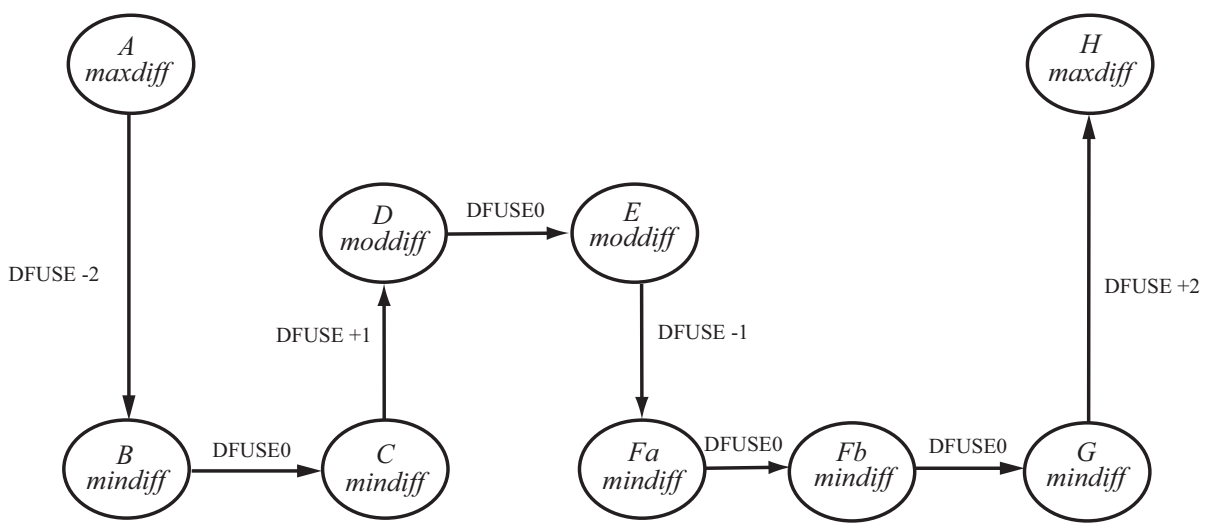

(b) Sec1' (Orchestra II, mm. 38-47)

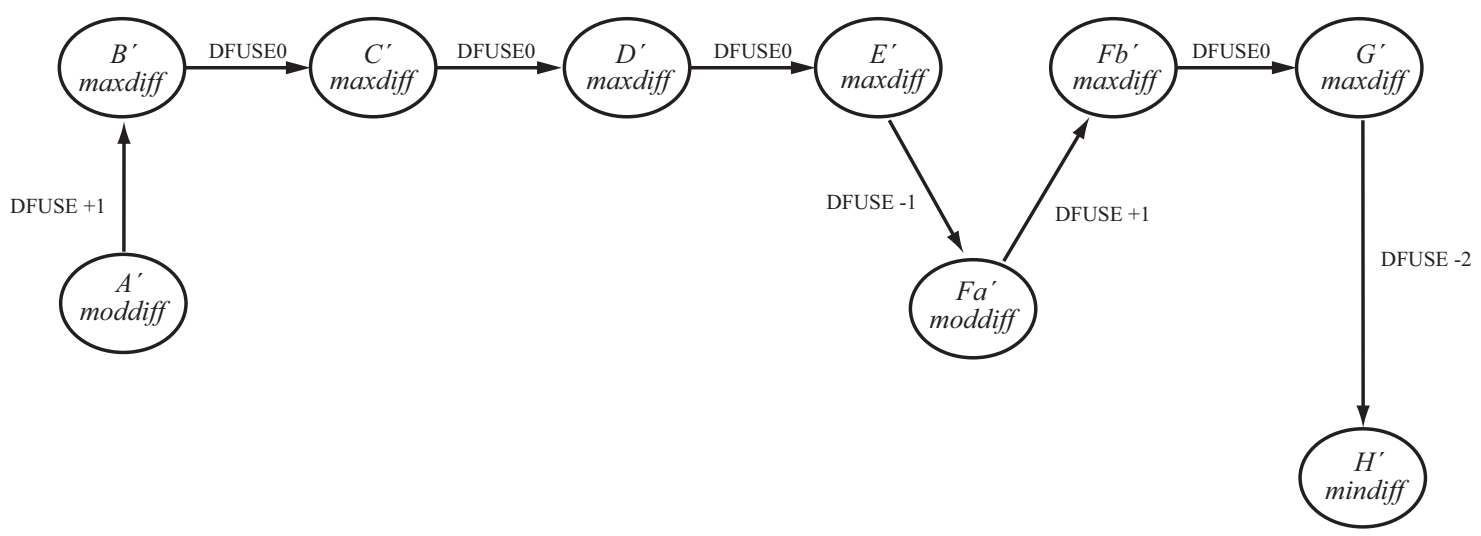

example 9. Density Compression Networks. (a) Sec1 (Orchestra I, mm. 26-35). (b) Sec1' (Orchestra II, mm. 38-47).

discussions, where at stake is the accepted notion that analytic endeavors are not just forms of subjective interpretation but also pleas for certain kinds of understanding. ${ }^{34}$ Indeed, an analysis can be envisaged as a performance-an enaction - of understanding which aims to convince readers to participate in the epistemological and experiential landscapes it reveals. It can propose a certain kind of hearing, thereby effecting a

34 For particularly engaging and multifaceted discussions of this strain focused around the issues of "structural listening," see the essays in Dell'Antonio (2004), especially Dubiel's "Uncertainty, Disorientation, and Loss as Responses to Musical Structure.” See also Rings (2011b) for a brief state-of-the-field overview of the emerging friction between analysts who embrace, or at least try to account for, the experiential implications of Lewin's transformations, and those for whom such implications are of lesser concern. potential to shape phenomenal experience and alter one's perception. ${ }^{35}$ Keeping in mind the consequences of analysis on our hearing, we may wonder whether the proposal in Part I-

35 See especially Agawu (2004), as well as Guck (2006) and Parkhurst (2013). Moreover, explicit gestures toward the interrelation between analysis and hearing can be found in numerous passages throughout Lewin's writings. One especially striking example, which is subtly revealing as well as implicitly value-laden, occurs in his discussion of the Minuet from Beethoven's First Symphony (see Lewin 1987, 169ff.). Here, Lewin writes of an "old-fashioned way of hearing" the movement's opening, thus exposing to interpretation and critique different pronouncements analysts make with respect to the products of their labor. Of course, Lewin himself does not explicitly pass judgment on which hearing is "better"; quite the contrary, by analogy with the mercurial $\mathrm{Mr}$. X, he points the reader to consider the benefits of a shift in hearing. However, one could easily imagine constructing an argument in which a "contemporary" hearing replaces the 

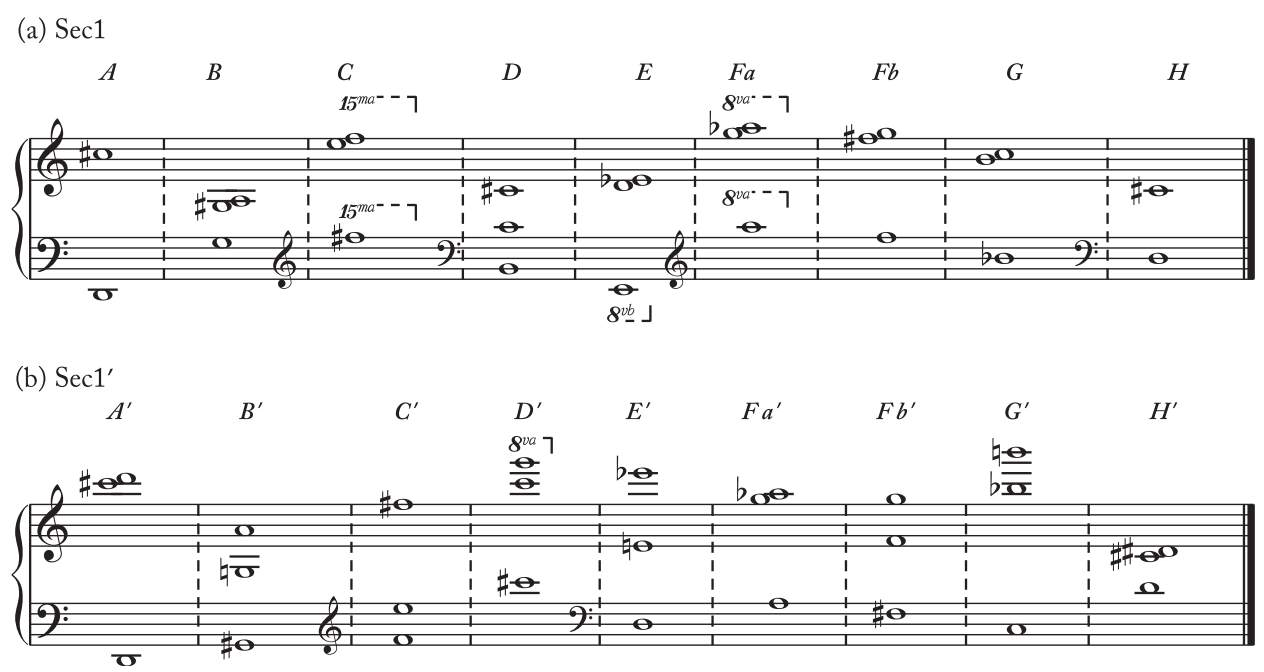

EXAMple io. A piano realization of $\operatorname{Sec} 1$ and $\operatorname{Sec} 1$ '
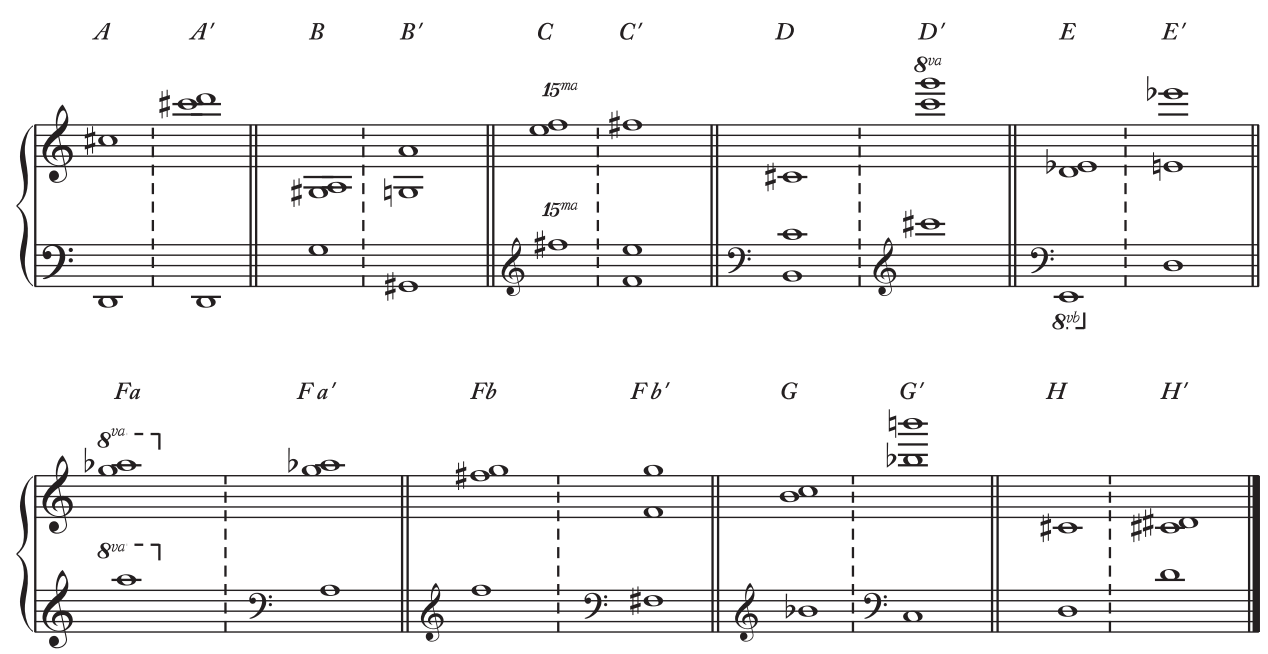

EXAMPle II. A piano realization of pitch mappings between corresponding chords form Sec1 to Sec1'

that is to say, one that suggests hearing this passage in Threnody with an ear for exact transformations of a handful of pitch elements embedded in a thick texture of pointillistic timbral and percussive effects-is even appropriate for this piece. ${ }^{36}$ Regardless of one's epistemology of analysis, the potential fallacy of such an enterprise is what Rings (sardonically, no doubt) calls "the most time-honored value of modernist music

"old-fashioned" based on any number of methodological and perceptual merits.

36 Indeed, such criticism would not be unprecedented with respect to sonoristic repertoire (see, for example, Cone [1960]; for a rebuttal, see Morgan [1977]; for recent commentaries on the "myth" concerning serialism in composition and perception, see Straus [2008] and Hermann [2011]). theory" which is "the demonstration of coherence through formalism." ${ }^{37}$ We can easily compare this situation to being asked to see regular organization and intelligible patterns in Jackson Pollock's drip paintings. The problem, of course, is to insist on coherence even when such a demonstration takes us far beyond the limits of perception or when the hard-fought search results only in a Pyrrhic victory over what is purportedly meant to be an irrational visceral experience.

This problem is especially germane to transformational analysis. As posited by Julian Hook, compared to an analytic model like Schenker's, for example, transformational analysis largely depends on the analyst's own criteria for

37 Rings (2011a, 499). 
making almost all decisions, even at such a fundamental level as determining what sorts of musical elements to consider and which relationships between them to foreground. ${ }^{38}$ There is an infelicitous dearth of blueprints or prescriptions for this kind of approach, the only examples existing in the form of other analyses. ${ }^{39}$ The transformational technology is exceptionally flexible and broad-reaching in that one can easily adjust it to the particular circumstances of a piece or passage under consideration, but it supplies few rigorous guidelines for the analyst to follow. Thus, the responsibility of the latter is to justify her choices in terms that make the most sense musically. ${ }^{40}$

Given that the musical grammar in Threnody is so idiosyncratic, one may be reasonably suspicious whether my justifications stem from musical intuitions-that is, whether they pertain to the experience of music. I could have easily forgone positing any relevance that these particular pitch collections and the relationships between them might have to listening, instead simply asserting their presence based on a close reading of the score. However, as I will show below, hearing these collections in this particular way does have a significant impact on how I (at least) experience Threnody. ${ }^{41}$ More than that, it does so in ways that reveal aspects of the passage that an "informal" hearing does not, aspects that might influence our interpretation of the work as a whole. Thus, I think it might be productive to frame the question in terms of what is gained and what is lost in various experiential domains when one engages in a transformational hearing of the middle section of this piece.

We should remind ourselves that to advocate a "coherent," less "disorienting" listening-along with the often-handcuffed concepts of "logic" and "unity" - carries with it a possible issue of value. The relationships between pitches and other sonic elements, here represented in the form of transformations, are unmistakably there, even if "there" means simply "in the score." The concern, however, is whether the transformations ought to be marked for hearing in such an obvious way. In fact, one could argue that a kind of incoherent, disorienting experience is exactly what Carter was extolling about Threnody: a visceral, unmediated, irrational, bodily reaction to primitive sounds. While by itself this does not deny the existence of some sort of a scaffold on which these sounds are built, it does call into question an interpretation of this

38 Hook (2007).

39 Even Lewin's own analyses offer but snapshots and partial guidelines on how to construct and, more importantly, use transformations in analytical engagements with real pieces of music. One exception to this is his extended reading of the second of Arnold Schoenberg's Drei Klavierstücke, Op. 11 (1994); however, there he limits himself to a specific subset of transformations: Klumpenhouwer Networks. More recently, Roeder (2009) attempts to rectify this lack of prescription by providing step-bystep instructions on how to choose musical objects and transformations.

40 Hook $(2007,166)$.

4I This is yet another gloss on Lewin's (1993) essay. scaffold as a source of structure and meaning for the listening experience. $^{42}$

Carter's praise for Threnody centers on the way in which the piece can appeal to listeners on a sensuous level. This suggests that if one favors a more cerebral encounter, one loses the immediacy of an embodied experience. Yet there is nothing necessarily standing in the way of structural listening productively underpinning sensation. Consider, for example, how the various networks offered in Part I crystallize a stable framework of auditory waypoints, which serve as articulations along a continuously changing surface of sonic objects. While such articulations may "rationalize" the act of listening, they also create the conditions for hearing part B in a particular relationship to its neighbors. Specifically, we can characterize the famous "screams" that open the piece as aggressively exposed and monolithic, their architecture laid bare by way of an audibly transparent process of change from one state to another. In the middle section, by contrast, sound events are almost filigree, and the visceral unrest at the surface belies the brittleness of their abstract design, as if the sonic objects that make them up were severely underdetermined. And in a sense, they are: if we acknowledge that the piece's "tangible" musical materials ${ }^{43}$ - sound masses and sound objects - exist in a dichotomous relationship, then all the different sonorities that fill part $\mathrm{B}$ straddle the line between them, always in danger of spilling over from one category into the other. A more holistic hearing that is attentive, for example, to the intensity of the passage might soak up this effect in its totality, glossing over the local, micro-scale details.

Then again, it is precisely these details that really stand out, at least in my auditory experience. It is the textural change from slow successions of clusters in part A to a pointillistic canvas of percussive effects, efflorescent rhythmic figurines, and exuberant ricochets around the pitch space in part $\mathrm{B}$ that draws attention to these very elements. And once attention is focused, once the auditory searchlight finds its targets, an entirely different path through the piece can emerge, one that suggests a much more lapidary effort in its design. Notice, for example, how the transformational ear-training model addresses the quick successions of pitches in eminently different ranges. Rather than obscuring this musical feature-say, under the guise of pitch classes-it explicitly draws attention to it and considers its central role in the formation of musical perceptions.

42 The question of value in musical structure with respect to experience and, more importantly, an understanding of music is perhaps most vehemently addressed by Rothgeb (1997). Although dealing with tonal repertoire, in this brief but example-rich essay, Rothgeb makes some very strong statements about the ethics of listening to that which is beyond salience. While his proclamations might sound somewhat misdirected in today's climate, there is a sense that the work we do leads to a particular kind of understanding of the music we write about. It seems justifiable, therefore, to examine what kind of understanding one's analysis promotes and whether it does not lead to a misunderstanding.

43 Metzer $(2009,176)$. 
Turning therefore to a positive perspective of what one might gain experientially from a transformational ear-training approach, I am inclined to follow Judy Lochhead's optimistic assertion that "in principle any piece of music ... should be a potential subject for analytic understanding." ${ }^{\prime 4}$ The issue in achieving analytic understanding is not one of establishing a priori criteria - of structure, unity, coherence, and so forthbut one of justifying methodological choices in ways that make sense according to whatever framework in which one is operating and however one defines "understanding." The goal of such an endeavor would be, as Joseph Dubiel has put it, "to understand how the notes might interact with, specifically promote, my awareness of my own involvement in the forming of [musical] perceptions. ${ }^{35}$ In other words, such an approach reinserts the analyst into the analysis as an intentional agent conscious of the volitional aspect of listening. Listening thus becomes mindfully active, which is to say that the analyst is attentive to and cognizant of the very process of this becoming, this activation. As a result, structure can retain its formative function in experience while eschewing both overarching narratives and "analyst-as-cryptographer-to-music'sEnigma-machine" approaches that seek to "decipher" musical codes. ${ }^{46}$ Once again, this line of inquiry allows us to defer to Lewin, in particular his suggestion that a more interesting alternative to the question, "Can you hear this?" is whether or not, following some kind of prescription, one's hearing is satisfying. ${ }^{47}$

Lewin's proposal bases analytical credibility on experiential imprints made on the listener, including the analyst, by various musical relationships. Of course, there is no escaping the inherent subjectivity, multivalence, and contingency of the concept of satisfaction with respect to hearing formally justified and prescribed structures, and Lewin likely left it as general as possible in order to allow a wide variety of experiences to undergird analytical understanding. To productively circumscribe this concept for our discussion we can think of analysis that prescribes a particular listening strategy as satisfying if it manages to somehow extend our hearing in a way that is beneficial and prolific. Considered in this light, accepting the sonorities foregrounded above as structural throws into relief other elements as participating in the creation of a particular musical experience, and so opens the discussion by showcasing a novel way of perceptually organizing these sounds. To illustrate what I mean, let us return to Threnody.

An obvious way in which the ear-training model extends our hearing is by providing points of orientation in the process of sonic unfolding: a way of letting the listener hear whether she is in the middle of a large-scale phrase, coming to the end, or at the point of initiating a new phrase. However, this can be accomplished through means other than transformational

44 Lochhead (2006, 233).

45 Dubiel $(2004,196)$, emphasis added.

46 For a similar view, see Quinn (2006).

47 Lewin $(1993,44)$. hearing, for example by simply reacting to isolated moments in the sonic flow. A nice illustration of such a moment occurs in Threnody at mm. 36-37 (and then again in mm. 48-49), where the forward movement is halted and the tremolo sonority is sustained longer than anything that came before. Here, one need not have a sense of how this event participates in the overall design - how the music arrived here, and where it will proceed in the immediate future-in order to discern that it is some kind of a repose in the middle of an otherwise very active succession of sounds.

In contrast to such an austere listening, in which attention remains at the phenomenal surface of music, my approach is significantly more complex. One challenging aspect of Threnody is how its two outer parts (A and A') seem sonically, technically, and experientially at odds with the middle (B). To alleviate this concern we could dismiss the entire enterprise as a "study in sound masses"-befitting its original title-and consign its intricate organization to some abstract structure that was never meant to be heard anyway: ostentatious (or worse, pretentious) compositional frippery that lacks any audible correlation. But I think that instead of supporting such a dismissal, my transformational ear-training process can actually shed some important light on the overall experience of the piece.

Without an awareness of a coherent design, events in $\mathrm{mm}$. 26-48 simply go by too quickly for me to grasp their significance in the flow of sounds. However, even in Threnody, this difficulty with actively listening in real time does not, by itself, invalidate a perception of logic and coherence, given the right musical context. For example, it is plausible for a listener to perceive the slow and gradual changes between different types of clusters in mm. 1-25 as some sort of a lucid whole. ${ }^{48}$ The conception of this organization can then be stored in longterm memory and, in turn, help the listener structure other parts of the piece. This seems to be a result of a number of factors. In my experiences listening to the piece, the overall rate of change here is rather unhurried, which allows me to conceptualize each sound as a clearly defined element and categorize it according to whatever apperceptions I might have. There is also a progressive, directed morphology from one sonic event to the next-a "good continuation" of sorts, which arises as a result of transformations between the elements. For example, despite the subito drop in dynamics from fortissimo to forte in m. 2, it is possible to hear the opening cluster as smoothly transformed from stationary to oscillating by the addition of wide and narrow vibrato. Indeed, much of the first part of Threnody (mm. 1-25, with the possible exception of mm. 6-9) consists of slow and steady developments of sounds, either through continual modulation of a single sonic parameter or by a gradual imposition of one element on another. Thus, it is not difficult to perceive a coherent design in this part: the listener has plenty of time to become familiar with each sound, which makes it possible to predict and to anticipate 
the next sound by applying some previously encountered transformation.

In contrast, events in $\mathrm{mm}$. 26-48 succeed one another very quickly. Given the time of fifteen seconds for each section of the score and its division into six measures, we can calculate $\mathrm{MM}=75$ for each quarter. Some "beats" are then further subdivided down to quintuplet and sextuplet sixteenth notes. Under these circumstances, changes in pitches and articulations occur so rapidly that my ability to process them in real time diminishes dramatically. An attempt to pick out every one of them, and to analyze them in the manner presented in the preceding paragraph, requires a very unique, specialized type of hearing. However, focusing on slower-moving sonic segments, ones that can be easily discerned based on their pitch structure, provides me with a listening model that omits certain sounds that have entirely different spectral envelopes (in this case, elements $\mathrm{P}$ and $\mathrm{An}$ ) in order to follow the passage consistently from start to finish. Furthermore, this transformational model shows a continuity in certain pitches and articulatory elements that allows me to pay attention to the progression of the passage. The key factor here is that an intuition of transformations relating one pitch structure to the next consistently helps me anticipate and act upon (rather than be surprised by and react to) pitch successions. Thus, it becomes easier for me to hear this music without "getting lost" in its complexity.

Earlier I made a point that, despite forfeiting intensity, having a roadmap through Threnody lets us hear part $\mathrm{B}$ as distinct from parts A and A'. Here, I actually want to nuance this claim by adding that a transformational hearing of the passage in question stimulates a new way of thinking about the three parts of Threnody as different perspectives on the same process. This process is readily audible in the outer sections, but remains obscured in the middle. One way to think about it is as if in part $\mathrm{B}$ the outside of $\mathrm{A}$ and $\mathrm{A}^{\prime}$ becomes the inside, but now only as scaffolding. Rather than juxtaposing opposites, this shift of perspective gives the entire piece a large-scale arch form by showcasing different features of the same type of sonic event. Whereas the outer parts exhibit dense chromatic clusters that are built through expansions and contractions of pitch space, and by gradual additive processes in the dimensions of pitch, timbre, dynamics, percussive effects, and so forth, in part B the sound mass itself becomes the process: by manipulating the pitch content and diffusion of each trichord, Penderecki uses them as sonoristic construction materials in their own right.

The above interpretation postulates a distinct category of musical elements situated somewhere between pointillismexemplified by such works as Stockhausen's Kreuzspiel (1951) and Boulez's Structures (1952) - and sound masses proper. With regard to the former, the effect of pointillism in these pieces is achieved by serial techniques applied to individual pitch-classes. In Threnody, by contrast, we can conceive of entire trichords as "points" that coalesce to make up the whole, a procedure that draws the middle part conceptually closer to the outer ones. By tracking transformations between trichords and attending to a network that relates all of them in some coherent manner, we can arrive at a different understanding of the term "sound mass." To return to Mirka's exposition of structural features in Penderecki's oeuvre, in which she considers the use of masses as building blocks, the trichords here fulfill precisely that role. ${ }^{49}$ When taken as indissoluble but flexible units, rather than ad hoc amalgams that merely fall out of a pre-compositional algorithm, they behave like registrally expanding and contracting pockets that support an effervescent musical surface.

We can thus construe Penderecki's 8'37'-a seemingly straightforward "study in sound masses"-as a very sophisticated manipulation of intricate sonic elements. While this approach may miss out on the raw physical and emotional impact of Threnody lauded by Carter, it foregrounds a no less important aspect of the piece, an aspect with real consequences for the listening experience. Namely, it directs listeners' attention to the "constructedness" (to borrow from Dubiel) of the large-scale design, whereby part $\mathrm{B}$ is no longer heard as musically separate from its neighbors. ${ }^{50}$ As in the bookend sections, it retains chromatic clusters as a structural element and links experientially all three sections of the piece. The transformational ear-training proposed above also functions in reconfiguring the visceral, embodied reaction of listeners by actively shaping their affective responses. Instead of idly letting the music direct the intensity of experience, they can now participate in what one could call "experimental" listening: a continuous renewal of interpretation though repeated, controlled auditory trials.

But, in a way, this is where we have been all along. Recall the Pollock comparison mentioned earlier, which implied that seeing coherent patterns in his drip paintings might be detrimental—or, at the very least, extraneous - to one's experience of them. When we look at the surface of these paintings, we are implored to gaze past and transcend the limits of their physicality, their materiality. As viewers, our job is to aestheticize the disembodied effects of real-world movements and not the movements themselves. But we must also note that there is a complex relationship between Pollock's literal strokes-gestures of his arms and hands-and the painted surface of his artworks. The former are limited to the actions that are physically feasible, whereas in the latter we recognize these limitations in the patterns that we see. This may be why it is, in fact, possible to observe intelligible shapes to begin with: a circle reminiscent of a cartoon face here, a zigzag suggestive of a mountain range there, all somehow indexing the body that created them. Considered in these terms, the experiential effect has a striking connection with Carter's assessment of Threnody. Specifically, the lack of readily rationalized musical structures forces the listener to "[search] into the physical aspects of musical production." But even though it may seem like those very aspects are raw and unmediated, they are both already structured-by the instruments that are played, by the performers'

49 Mirka (2000).

5o Dubiel (2004). 
bodies and their capabilities, by Penderecki's directions, and so on - and also structuring of experience. In consequence, there is no escaping the organizing impulse of experience; what my analysis presents is simply a different way of succumbing to it.

\section{WORKS CITED}

Adorno, Theodor W. 2002. "On the Problem of Musical Analysis (1969)." Essays on Music. Ed. Richard Leppert, trans. Susan H Gillespie. Berkeley: University of California Press.

Agawu, V. Kofi. 2004. "How We Got Out of Analysis and How to Get Back In?” Music Analysis 23 (2-3): 267-86.

Berry, Wallace. 1987. Structural Functions in Music. New York: Dover.

Carter, Elliott. 1963. "Letters from Europe." Perspectives of Nerw Music 1 (2): 195-205.

-1 1995. "ISCM Festival, Amsterdam (1963/94)." Elliott Carter: Collected Essays and Lectures, 1937-1995. Ed. Jonathan Bernard. Rochester, NY: Rochester University Press.

Clarke, Eric. 2005. Ways of Listening: An Ecological Approach to the Perception of Musical Meaning. New York: Oxford University Press.

Cone, Edward T. 1960. "Analysis Today.” Musical Quarterly 46 (2): 172-88.

Cox, Arnie. 2011. "Embodying Music: Principles of the Mimetic Hypothesis." Music Theory Online 17 (2).

Dell'Antonio, Andrew, ed. 2004. Beyond Structural Listening? Postmodern Modes of Hearing. Berkeley: University of California Press.

Dubiel, Joseph. 2004. "Uncertainty, Disorientation, and Loss as Responses to Musical Structure." In Beyond Structural Listening? Postmodern Modes of Hearing. Ed. Andrew Dell'Antonio. 173-200. Berkeley: University of California Press:.

Dubois, Didier, and Henri Prade. 1980. Fuzzy Sets and Systems. New York: Academic Press.

Erhardt, Ludwik. 1975. Spotkania z Krzysztofem Pendereckim. [Encounters with Krzysztof Penderecki]. Warszawa: Polskie Wydawnictwo Muzyczne.

Godøy, Rolf Inge. 2010. "Gestural Affordances of Musical Sound." In Musical Gestures: Sound, Movement, and Meaning. Ed. Rolf Inge Godøy and Marc Leman. 103-25. New York: Routledge.

Granat, Zbigniew. 2008. "Editorial.” Muzyka 208 (1): 3-6.

Gruhn, Wilfried. 1971. "Strukturen und Klangmodelle in Penderckis Threnos." Melos 10: 409-11.

Guck, Marion. 2006. "Analysis as Interpretation: Interaction, Intentionality, Invention.” Music Theory Spectrum 28 (2): 191-209.

Harley, Maria Anna. 1998. "The Polish School of Sonorism and Its European Context." In Crosscurrents and Counterpoints: Offerings in Honor of Bengt Hambraeus at 70.
Ed. F. Broman, Nora Engebretsen, and Bo Alphonce. 62-77. Göteborg: University of Gothenburg.

Harrison, Daniel. 2011. "Three Short Essays on NeoRiemannian Theory." In The Oxford Handbook of Neo-Riemannian Theory. Ed. Edward Gollin and Alexander Rehding. 548-77. New York: Oxford University Press.

Hermann, Richard. 1995. "Theories of Chordal Shape, Aspects of Linguistics and Their Roles in an Analysis of Pitch Structure in Berio's Sequenza IV for Piano." In Concert Music, Rock, and Jazz since 1945: Essays and Analytical Studies. Ed. Elizabeth West Marvin and Richard Hermann. 364-98. Rochester: University of Rochester Press.

—. 2011. "Early Serialism in the United States: Aspects of Theory, History, Analysis, and Reception." Theoria 18: 110-37.

Hook, Julian. 2007. "David Lewin and the Complexity of the Beautiful.” Intégral 21: 155-90.

Lochhead, Judy. 2006. "'How Does It Work?': Challenges to Analytic Explanation." Music Theory Spectrum 28 (2): 233-54.

Klumpenhouwer, Henry. 2006. "In Order to Stay Asleep as Observers: The Nature and Origins of Anti-Cartesianism in Lewin's Generalized Musical Intervals and Transformations." Music Theory Spectrum 28 (2): 277-89.

Koblyakov, Lev. 1977. "Boulez's Le marteau sans maître: Analysis of Pitch Structure." Zeitschrift für Musiktheorie 8 (1): 24-39.

Kozak, Mariusz. 2015. "Listeners' Bodies in Music Analysis: Gestures, Motor Intentionality, and Models." Music Theory Online 21 (3).

Lewin, David. 1986. "Music Theory, Phenomenology, and Modes of Perception." Music Perception 3 (4): 327-92.

-1987. Generalized Musical Intervals and Transformations. New Haven: Yale University Press.

-1993. Musical Form and Transformation: Four Analytic Essays. Hew Haven: Yale University Press.

- 1994. "A Tutorial on Klumpenhouwer Networks, Using the Chorale in Schoenberg's Op. 11, No. 2.” Journal of Music Theory 38 (1): 79-101.

London, Justin. 2012. Hearing in Time: Psychological Aspects of Musical Meter. New York: Oxford University Press.

Metzer, David. 2009. Musical Modernism at the Turn of the Twenty-First Century. Cambridge: Cambridge University Press.

Mirka, Danuta. 1997. The Sonoristic Structuralism of Krzysztof Penderecki. Katowice: Music Academy in Katowice.

—. 2000. "Texture in Penderecki's Sonoristic Style." Music Theory Online 6 (1).

Morgan, Robert. 1977. "On the Analysis of Recent Music." Critical Inquiry 4 (1): 33-53.

Morris, Robert. 1995. "Compositional Spaces and Other Territories." Perspectives of Nerw Music 33 (1-2): 328-58.

Nattiez, Jean-Jacques. 1990. Music and Discourse: Toward a Semiology of Music. Trans. Carolyn Abbate. Princeton: Princeton University Press. 
Parkhurst, Bryan. 2013. "Fraught with Ought: An Outline of an Expressivist Meta-Theory." Music Theory Online. 19 (3).

Quinn, Ian. 1997. "Fuzzy Extensions to the Theory of Contour." Music Theory Spectrum 19 (2): 232-63.

- 2006. "Minimal Changes: Process Music and the Uses of Formalist Analysis." Contemporary Music Review 25 (3): 283-94.

Rings, Steven. 2011a. "Riemannian Analytical Values, Paleoand Neo-." In Oxford Handbook of Neo-Riemannian Theory. Ed. Edward Gollin and Alexander Rehding. 486-511. New York: Oxford University Press.

- 2011b. Tonality and Transformation. New York: Oxford University Press.

Roeder, John. 2009. "Constructing Transformational Signification: Gesture and Agency in Bartók's Scherzo, Op. 14, No. 2, measures 1-32." Music Theory Online 15 (1).

Rothgeb, John. 1997. "Salient Features." In Music Theory in Concept and Practice. Ed. James Baker, David Beach, and Jonathan Bernard. 181-96. Rochester: University of Rochester Press.

Stewart, John, Olivier Gapenne, and Ezequiel A. Di Paolo., eds. 2010. Enaction: Toward a New Paradigm for Cognitive Science. Cambridge [MA]: MIT Press.

Straus, Joseph N. 2008. "A Revisionist History of TwelveTone Serialism in American Music." Journal of the Society for American Music 2 (3): 355-95.

Subotnik, Rose Rosengard. 1995. Deconstructive Variations: Music and Reason in Western Society. Minneapolis: University of Minnesota Press.

Taruskin, Richard. 2005. Oxford History of Western Music. New York: Oxford University Press.

Thomas, Adrian. 2005. Polish Music Since Szymanowski. Cambridge: Cambridge University Press.

Varela, Francisco, Evan Thompson, and Eleanor Rosch. 1991. The Embodied Mind: Cognitive Science and Human Experience. Cambridge [MA]: MIT Press.

Zielinski, Tadeusz. 1968. "Technika Operowania Instrumentami Smyczkowymi w Utworach Krysztofa Pendereckiego.” [Techniques of Employing String Instruments in the Works of Krzysztof Penderecki]. Muzyka 13 (1): 74-92.

Music Theory Spectrum, Vol. 38, Issue 2, pp. 200-17, ISSN 0195-6167, electronic ISSN 1533-8339. (C) The Author 2017. Published by Oxford University Press on behalf of The Society for Music Theory. All rights reserved. For permissions, please e-mail: journals.permissions@oup.com. DOI: $10.1093 / \mathrm{mts} / \mathrm{mtw} 015$ 